\title{
Breeding of a new wastewater treatment yeast by genetic engineering
}

Miyoshi Kato ${ }^{1}$ and Haruyuki lefuji ${ }^{1,2^{*}}$

\begin{abstract}
We previously developed a host vector system for the wastewater treatment yeast Hansenula fabianii J640. The promoter and terminator regions of the gene encoding glucoamylase from $\mathrm{H}$. fabianii $J 640$ were used for a new expression vector, pHFGE-1. The performance of pHFGE-1 was compared with that of the widely used pG-1 transformant vector. H. fabianii J640 (HF-TAMY) cells were transformed with pHFGE-1, and Saccharomyces cerevisiae YPH-499 (SC-TAMY) cells were transformed with pG-1, both of which carried the Taka-amylase. Expression of Takaamylase by HF-TAMY showed higher than that by SC-TAMY. By using this new system, we bred the new wastewater treatment yeast that shows $\alpha$-amylase activity. This yeast appears to grow well under experimental wastewater conditions, and is effective in treating model wastewater containing soluble and insoluble starch.
\end{abstract}

\section{Introduction}

Many food factories use wastewater treatment systems that use yeasts (Yoshizawa 1978,, 1981,, Sato et al. 1986,, Moriya et al. 1990,, Suzuki et al. 1991,, Suzuki et al. 1996). However, some wastewater-containing polysaccharides, such as raw starch and hemicellulose, are difficult to treat because presently used yeasts secrete few enzymes that can digest these polysaccharides. One way to treat these wastewaters is to transform conventional wastewater treatment yeasts with the genes for polysaccharide-digesting enzymes such as raw starch-digesting $\alpha$-amylase and acid xylanase.

To this end, we isolated Cryptococcus sp. S-2 (Iefuji et al. 1994,), which secretes several enzymes including raw starch-digesting $\alpha$-amylase (Iefuji et al. 1996a,), acid xylanase (Iefuji et al. 1996b,), lipase (Kamini et al. 2000) and polygalacturonase. We then obtained the genes that encode the raw starch-digesting $\alpha$-amylase and acid xylanase.

H. fabianii $\mathbf{J} 640$ is a commonly used wastewater treatment yeast (Saito et al. 1987, Sato et al. 1987,, Suzuki et al. 1996,). We previously constructed an expression system based on this strain (Kato et al. 1997). A uracil auxotrophic mutant of $H$. fabianii J640, named H. fabianii J640 u-1, lacking orotidin-5'-phosphate decarboxylase, was

\footnotetext{
* Correspondence: iefuji@nrib.go.jp

${ }^{1}$ Graduate School of Biosphere Science, Hiroshima University, 1-4-4,

Kagamiyama, Higashihiroshima, Hiroshima 739-8527, Japan

Full list of author information is available at the end of the article
}

obtained. We constructed a plasmid, pHFura3, that contains the gene encoding orotidine-5'-phosphate decarboxylase of H. fabianii J640. In the previous study (Kato et al. 1997), by employing H. fabianii J640 u-1 as a host strain and pHFura3 as a vector plasmid, we constructed a transformation system of $H$. fabianii $\mathbf{J} 640$.

We purified the glucoamylase of $H$. fabianii $\mathrm{J} 640$ and cloned its cDNA and genomic DNA (Kato et al. in press). Then, we constructed a new expression vector, pHFGE-1 (Kato et al. in press), which uses pHFura3, and the promoter and terminator regions of the gene encoding glucoamylase from $H$. fabianii J640. We inserted the genes encoding $\alpha$-amylase and xylanase from Cryptococcus sp. S-2 between the promoter and terminator of pHFGE-1. When the pHFGE-1 with one or the other of these foreign genes were transformed into $H$. fabianii $6640 \mathrm{u}-1$, the transformants (named HFAAMY and HF-XYN, respectively) showed $\alpha$-amylase and xylanase activities respectively. This showed that pHFGE-1 can derive the expression of foreign genes in H. fabianii $\mathbf{J} 640$ cells.

In this paper, we investigated the ability of these transformed yeasts, to treat wastewater, and developed a PCR method for monitoring the presence of the foreign gene.

\section{Materials and methods Strains and media}

Strains H. fabianii J640 and Cryptococcus sp. S-2 were obtained from the National Research Institute of Brewing

\section{SpringerOpen $^{\odot}$}


culture collection, Japan. A uracil auxotrophic mutant of $H$. fabianii J640, named $H$. fabianii J640 u-1, lacking orotidine-5'-phosphate decarboxylase, was used as a host strain for new expression vector pHFGE-1. S. cerevisiae YPH499 (MAT $\alpha$ ura3 lus2 ade2 trp1 his3 leu2) was used as the host for transformation vector pG-1 (Schena et al. 1991). E. coli strain HB101 and JM109 were employed as the host of plasmid vector, which were used for DNA manipulation and construction of the gene library.

Yeast cells were grown on YM medium $(0.3 \%$ yeast extract, $0.3 \%$ malt extract, $0.5 \%$ peptone and $1 \%$ glucose) and YPD medium (1\% yeast extract, $2 \%$ peptone, $2 \%$ glucose). Luria-Bertani medium containing ampicillin (100 $\mu \mathrm{g} / \mathrm{ml}$ ) was used to cultivate $E$. coli. The minimal medium containing $1 \%$ glucose and $0.67 \%$ yeast nitrogen base (YNB) without amino acids was used to select the yeast transformants. YPM medium was prepared by replacing the glucose of YPD with maltose. The medium used to investigate expression induction, contained $1 \%$ yeast extract, $1 \%$ casamino acid, and $2 \%$ glucose or maltose.

\section{Expression vector for $H$. fabianii $\mathrm{J} 640$}

The expression vector pHFGE-1 (Kato et al. in press) (Figure 1A) was used. The cloning site of this vector is a BamHI site between the promoter and terminator from H. fabianii J640 glucoamylase DNA. The host cell of this vector is a uracil auxotrophic mutant designated as H. fabianii $\mathrm{J} 640 \mathrm{u}-1$, and it could be transformed by a non-homologous and frequently multicopy integration into the host genomic DNA.

\section{Transformation of yeast}

Transformations were carried out by electroporation as described by (Becker et al. 1991). Electroporation was done with a Gene Pulser (Bio-Rad) with settings of 200 $\mathrm{V}$ and $25 \mu \mathrm{F}$ using a $0.2 \mathrm{~cm}$ cuvette.

\section{Assay of xylanase and $\alpha$-amylase activity}

Xylanase activity was assayed by measuring the amount of reducing sugar liberated from xylan (Iefuji et al. 1996b). One unit of activity was defined as the amount of xylanase needed to liberate $1 \mu \mathrm{mol}$ of $\mathrm{D}$-xylose per min under the condition just described.

$\alpha$-Amylase activity was measured with an $\alpha$-amylase kit (Kikkoman). One unit of $\alpha$-amylase activity was defined as the amount of enzyme which forms $1 \mu \mathrm{mol}$ of 2-choloro-4-nitrophenol from 2-choloro-4-nitrophenyl $6^{5}$-azide- $6^{5}$-deoxy- $\beta$ - maltopentaoside under the condition described above.

\section{Preparation of model wastewater and treatment test}

Model wastewater containing soluble starch was made with $1 \%$ refined starch (Merck) and $0.25 \%$ yeast extract, $\mathrm{pH}$ 6.0. The starch was solubilized by autoclaving. Model wastewater containing insoluble starch was made with $0.25 \%$ yeast extract, pH6.0, autoclaved and cooled to approximately $55^{\circ} \mathrm{C}$. The same amount of starch was sterilized in $70 \%$ ethanol. The suspension was centrifuged and decanted. The starch pellet was then added to the autoclaved yeast extract solution.

Yeast cells were incubated at $30^{\circ} \mathrm{C}$ for 2 days on YM medium. Then $5 \times 10^{6}$ cells $/ \mathrm{ml}$ was inoculated to the model wastewater in an Erlenmeyer flask. Cultures were incubated at $30^{\circ} \mathrm{C}$ with shaking at $105 \mathrm{rpm}$ and samples were periodically harvested.

Yeast cells in the model wastewater were counted with a hemocytometer

The model wastewater containing soluble starch was centrifuged at $3000 \mathrm{rpm}$ for $10 \mathrm{~min}$, and chemical oxygen demand (COD) of the supernatant was measured. The decrease in COD of the model wastewater containing

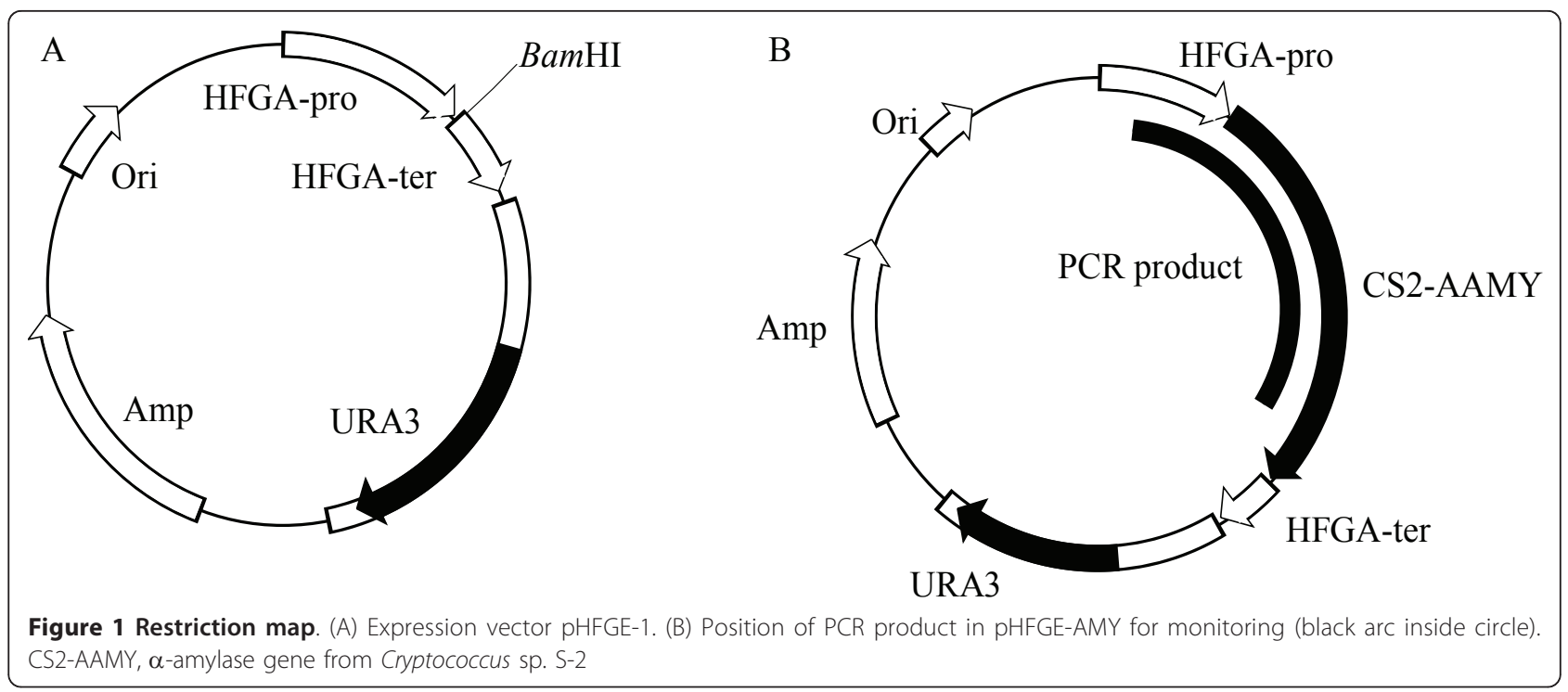


soluble starch was used to express the capacity of the yeast to treat the wastewater.

It was not possible to measure COD of the model wastewater containing insoluble starch because of the difficulty in separating the cells and insoluble starch. In this case, degradation of the starch was measured with the iodo-starch reaction (Sato et al. 1987) as follows: $1 \mathrm{ml}$ culture was heated in a micro tube at $100^{\circ} \mathrm{C}$ for $30 \mathrm{~min}$ to solubilize the starch. Yeast cells were then removed by centrifugation. Iodic liquid $(0.2 \mathrm{ml}$; containing $0.0317 \mathrm{~g}$ iodine, $0.1 \mathrm{~g}$ potassium iodide and $5 \mathrm{ml} 3 \mathrm{~N}-\mathrm{HCl}$ in 100 $\mathrm{ml}$ water) was added to the supernatant and the optical density was measured at $670 \mathrm{~nm}$. Transmittance at 670 $\mathrm{nm}$ was taken as a measure of starch degradation.

\section{Monitoring the presence of a foreign gene in a transformant}

The transformants were cultured in $10 \mathrm{ml}$ YM medium and harvested by centrifugation. DNA was extracted with an Easy-DNA kit (Invitrogen) and used for the PCR template. Unique PCR primers were designed, and the position of the PCR product is shown in Figure 1B. PCR cycling conditions were followed by 25 cycles of $94^{\circ} \mathrm{C}$ for $1 \mathrm{~min}, 55^{\circ} \mathrm{C}$ for $2 \mathrm{~min}, 72^{\circ} \mathrm{C}$ for $3 \mathrm{~min}$.

To determine the sensitivity of the PCR, cells were cultured in YM medium, and the cell density was measured. Then a dilution series was made $\left(10^{6}-10^{1}\right.$ cells $\left./ \mathrm{ml}\right)$. One $\mathrm{ml}$ of each dilution was harvested and DNA was extracted with the EASY-DNA kit and used as a PCR template.

\section{Results}

Induction of foreign gene expression

Glucoamylase production by $H$. fabianii J640 was induced by maltose and repressed by glucose. Since our constructed expression vector used the promoter and terminator regions of the $H$. fabianii $\mathbf{5} 640$ glucoamylase gene, we expected that foreign gene expression in the transformant would also be induced by maltose. As expected, xylanase production by HF-XYN was highest, when maltose was the $C$ source with yeast extract and casamino acid as media components (Table 1).

\section{Comparison of two vectors}

The performance of our expression vector pHFGE-1 was compared with that of the widely used pG-1 transformation vector. H. fabianii J640 u-1 (HF-TAMY) cells were

Table 1 Effect of media components on xylanase activity

\begin{tabular}{ll}
\hline Media composition & Xylanase activity $(\mathbf{U} / \mathbf{m l})$ \\
\hline Maltose, YNB w/o amino acids & 37 \\
\hline Maltose, Yeast extract, Casamino acid & 310 \\
\hline Glucose, YNB w/o amino acids & 1 \\
\hline Glucose, Yeast extract, Casamino acid & 6 \\
\hline
\end{tabular}

transformed with pHFGE-1, and S. cerevisiae YPH-499 (SC-TAMY) cells were transformed with pG-1, both of which carried the Taka-amylase gene. The cells were then cultured on YPD and YPM media. Growth on YPD medium was the same for the two cultures (Figure 2A). $\alpha$-Amylase activity was a little higher in the HF-TAMY cells than in the SC-TAMY (Figure 2B). The $\alpha$-amylase activity of HF-TAMY cells was highest when maltose was the $\mathrm{C}$ source (YPM medium, Figure 2D), indicating that gene expression was induced by maltose.

\section{Treatment of model wastewater}

HF-AAMY cells and cells of the parent strain $H$. fabianii J640 grew at about the same rate in the model wastewater containing soluble starch or insoluble starch (Figure $3 \mathrm{~A}$ or $4 \mathrm{~A}$ ). Both the parent strain and HFAAMY decreased the COD of the model wastewater containing soluble starch to decrease, although the decrease was much faster with the HF-AAMY cells (Figure 3B). The HF-AAMY cells were also much more efficient at degrading the insoluble starch (Figure 4B). These results indicate that HF-AAMY cells have a high capacity to treat wastewater containing starch.

\section{Monitoring of transformant by PCR}

Of four strains (S. cerevisiae YPH-499, Cryptococcus sp. S-2, H. fabianii J640 and HF-AAMY (the transformant)), only the transformant showed a PCR product (Figure 5A) corresponding to part of the HFGA promoter and the $\alpha$ amylase gene (Figure 1B). The detection sensitivity of PCR which uses Taq Plus Long PCR kit (Stratagene) was high, i.e., it could detect only $10^{4}$ cells (Figure $5 \mathrm{~B}$ ). The different intensities of the PCR bands in Figure $5 \mathrm{~B}$ are presumably the result of the different cell densities in the cultures.

\section{Discussion}

We developed a host vector system for the wastewater treatment yeast, $H$. fabianii J 640, and we created new wastewater treatment yeast transformants (HF-XYN and HF-AAMY). The expression of the foreign gene that was integrated in the transformant was induced by maltose and repressed by glucose. However, the growth rates of the transformants carrying pHFGE-1 and the widely used pG-1 were the same and both transformants strongly expressed the foreign gene, even in medium containing glucose, which was expected to repress expression of the foreign gene. Our host vector system strongly expresses the foreign gene. Because wastewater contains various components, the strong expression of the new strain is an advantage. The HF-AAMY cells were effective in treating the model wastewater.

Because HF-AAMY cells are genetically modified, a sensitive method for monitoring the cells in the 

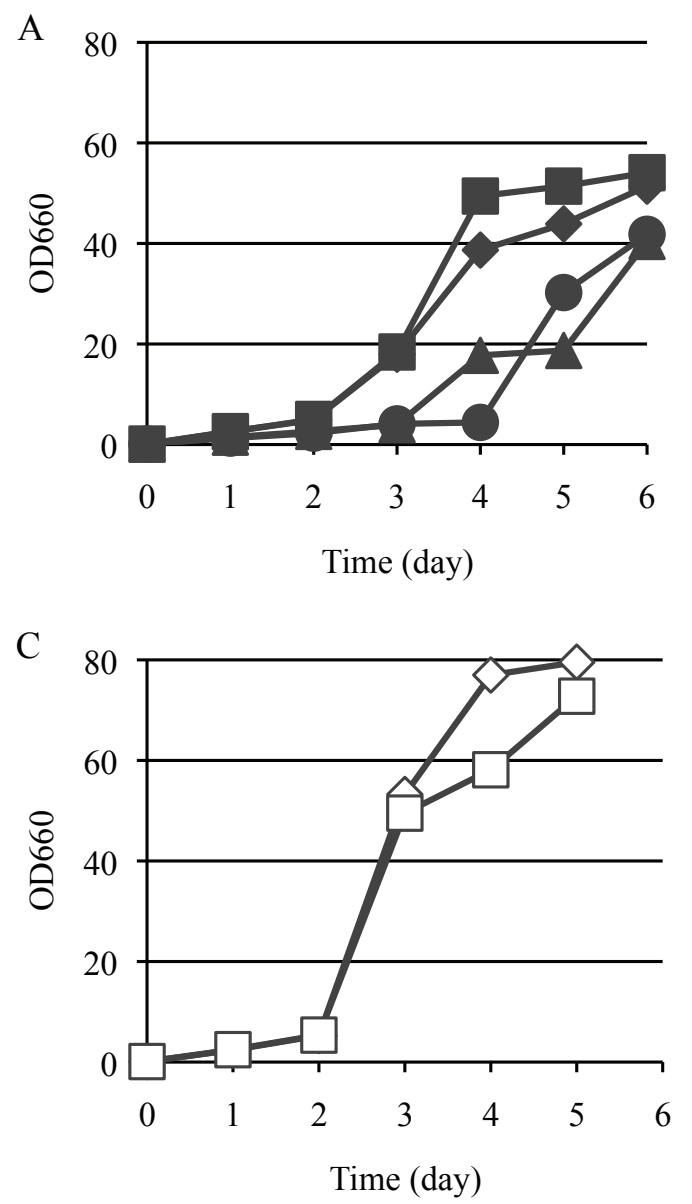
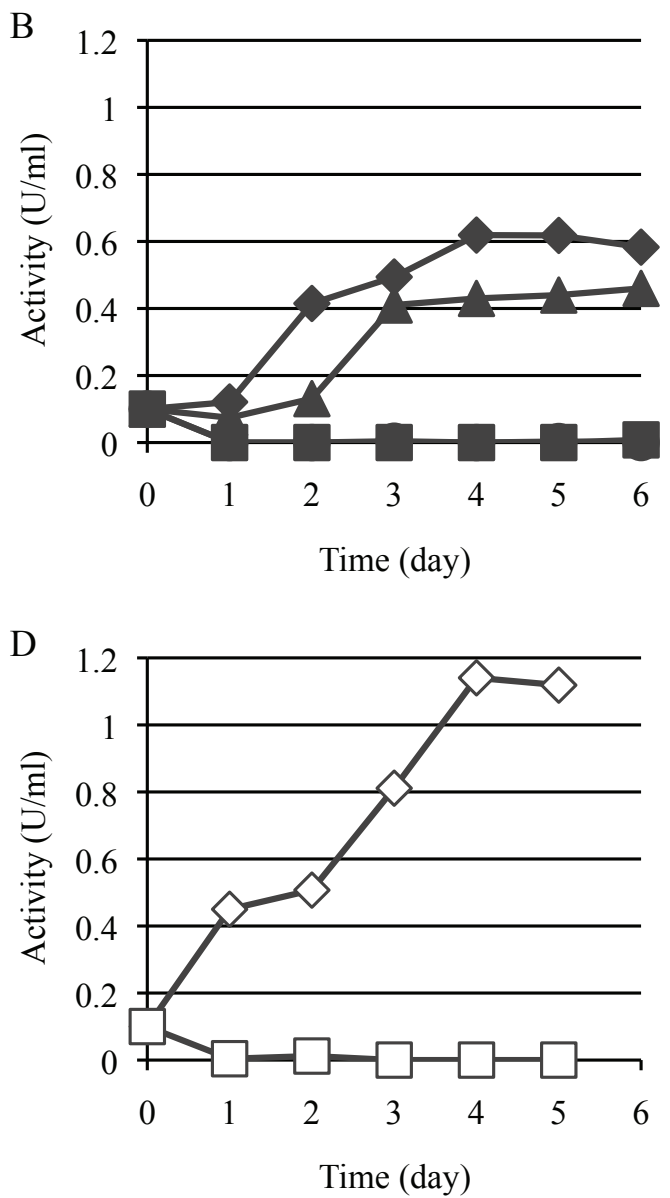

Figure 2 Comparison of two vectors and carbon sources. (A) Growth of transformants on YPD medium. (B) $\alpha$-Amylase activity of transformant on YPD medium. (C) Growth of transformants on YPM medium. (D) $\alpha$-Amylase activity of transformant on YPM medium. The strains are: HF-TAMY (diamonds), transformant with pHFGE-1 (not connected to any gene), into H. fabianii J640 u-1 (squares), SC-TAMY (triangles), transformant with pG-1 (not connected to any gene), into S. cerevisiae YPH-499 (circles).
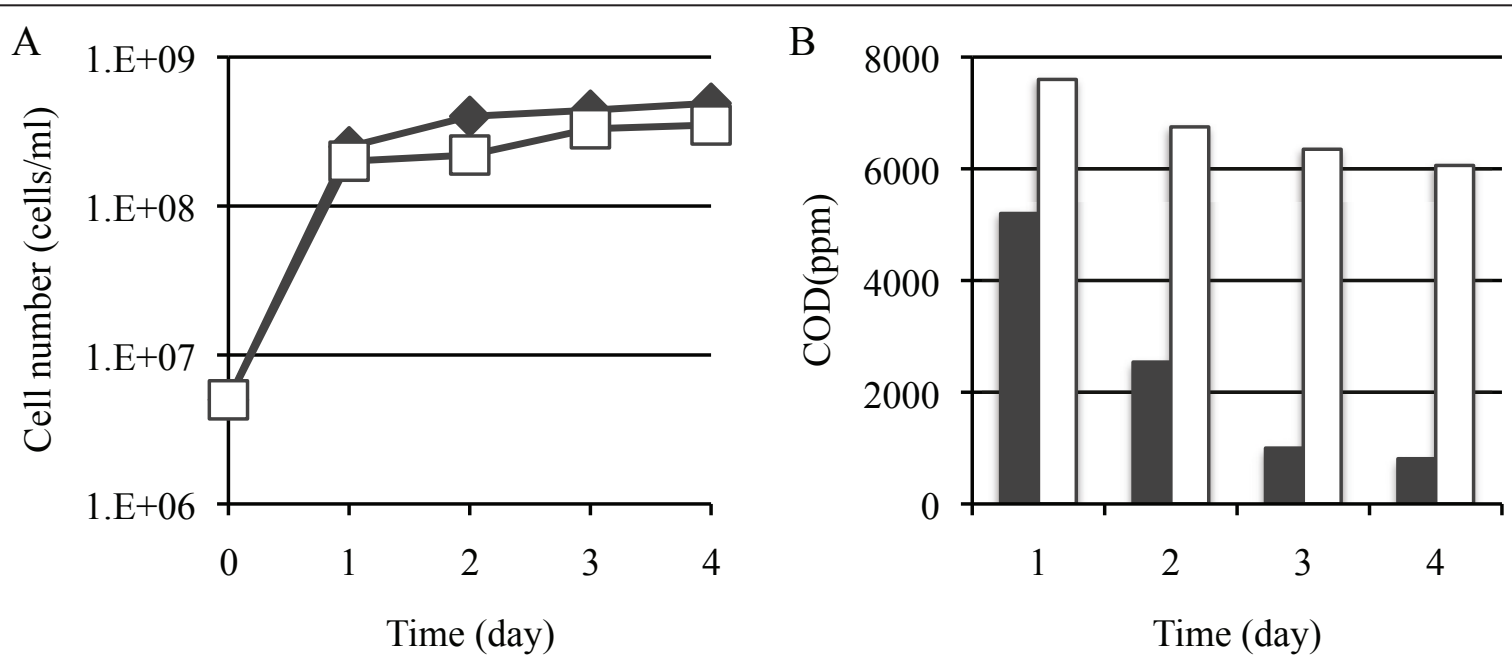

Figure 3 Treatment test of model wastewater containing soluble starch. (A) Growth rate of cells. (B) Decrease of COD. The strains are: HF-AAMY (diamonds, black bars), H. fabianii $J 640$ (host strain) (squares, white bars). 


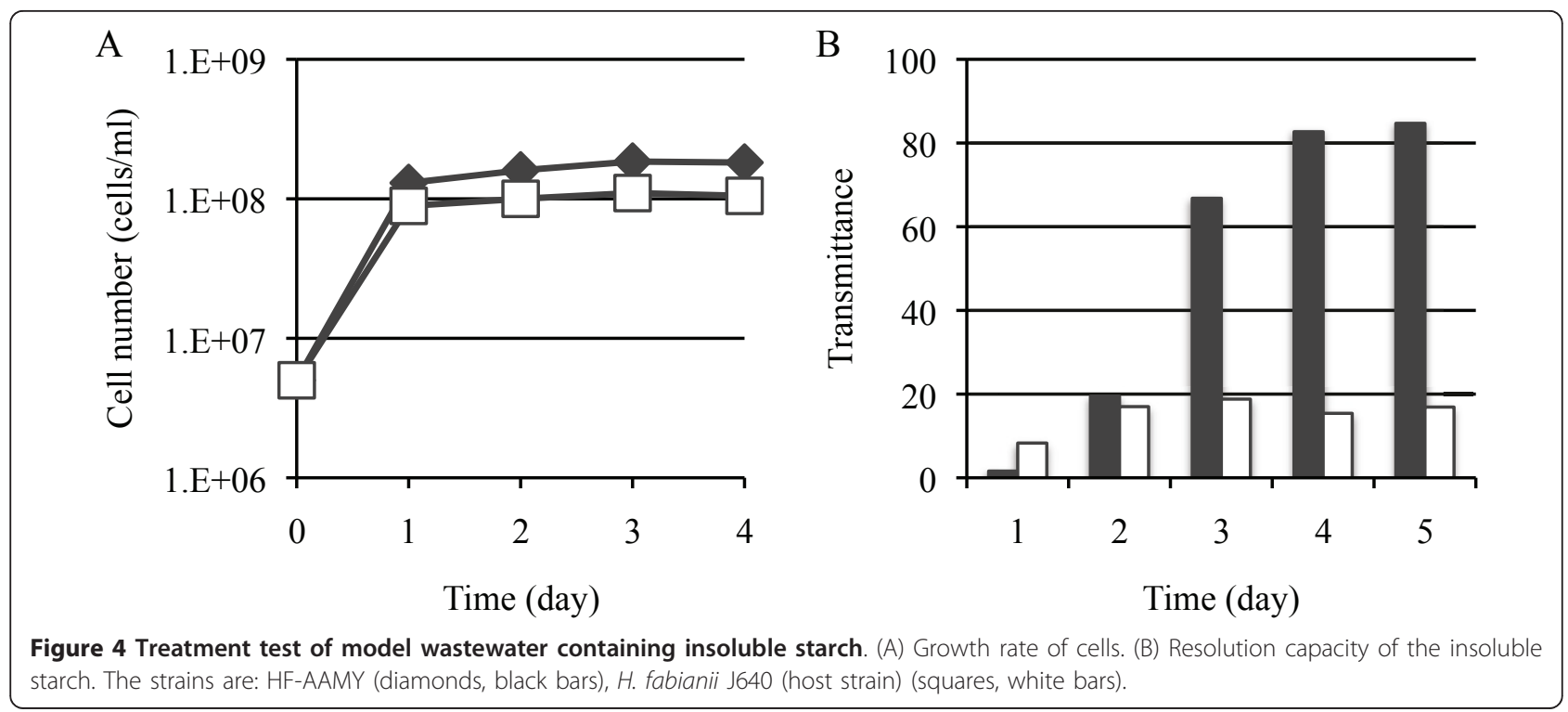

environment is needed. Our PCR was shown to satisfy this requirement.

A host vector system was also developed for the methylotrophic yeast Hansenula polymorpha (Gellissen et al. 2004,, Steinborn et al. 2006). As in these systems, auxotrophic strains (ura-, leu-) were used as the host. The expression cassettes in these systems used the promoters for various genes, including the genes for formate dehydrogenase (FMD), methanol oxidase (MOX), and trehalose-6-phosphate synthase (TPS1). H. polymorpha is rapidly becoming the system of choice for heterologous gene expression in yeast. Several production processes for recombinant pharmaceuticals and industrial enzymes have been developed based on gene expression in this strain. Another methylotrophic yeast, Hansenula ofunaensis, has also been evaluated for a transformation system (Yamada-Onodera et al. 1999,, Yamada-Onodera et al. 2006) but development has not been completed.

A transformation system using Hansenula anomala, another wastewater treatment yeast, was developed in
A

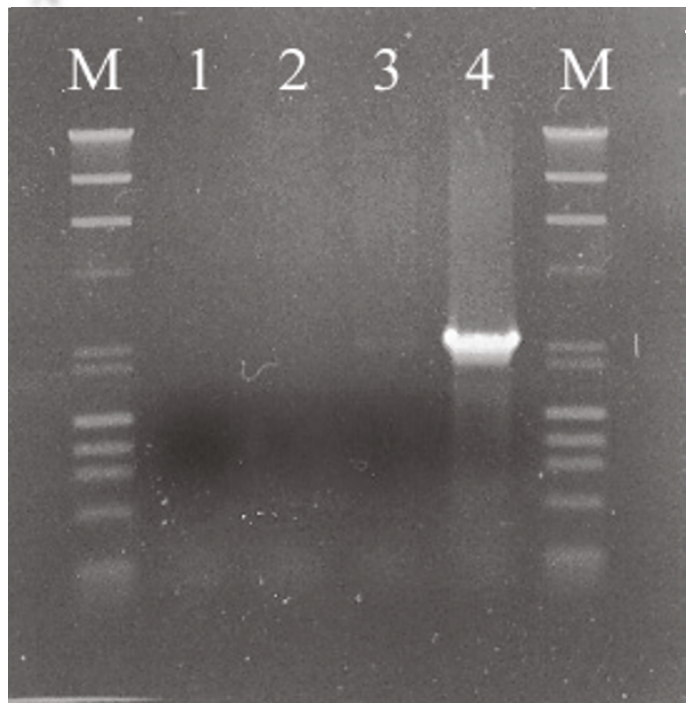

B

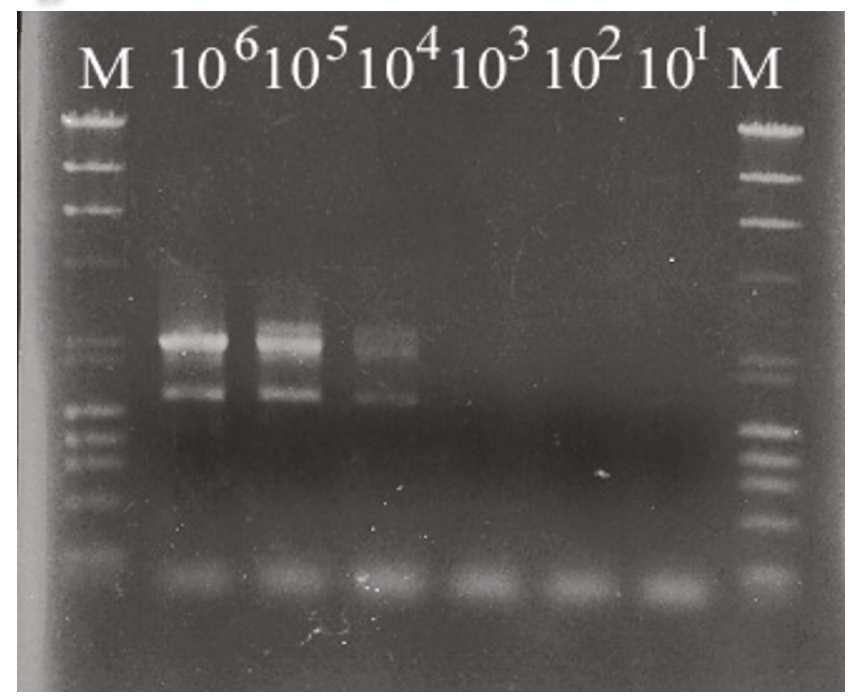

Figure 5 PCR test. (A) Specificity of PCR test for HF-AAMY cells. M, marker The strains are: (1) S. cerevisiae YPH-499, (2) Cryptococcus sp. S-2, (3) H. fabianii $\mathbf{5 6 4 0}$ (host strain), (4) HF-AAMY (transformant). (B) Sensitivity of PCR test. The number of cells in the reaction mixture are shown at the tops of the lanes. 
the 1990s (Ogata et al. 1992,, Ogata et al. 1995). However, none of these studies of wastewater treatment yeasts constructed an expression vector or bred new strains of yeast. With the new transformation system, it should be possible to treat wastewater containing polysaccharides that are presently resistant to degradation.

Our next goal is to use our transformant to treat real wastewater from the food industry. In the future, when genetically engineered yeast is proven to be effective for the treatment of wastewater, a major task will be to prove to the public that the methodology is safe.

\section{Author details}

'Graduate School of Biosphere Science, Hiroshima University, 1-4-4, Kagamiyama, Higashihiroshima, Hiroshima 739-8527, Japan ${ }^{2}$ National Research Institute of Brewing, 3-7-1, Kagamiyama, Higashihiroshima, Hiroshima 739-0046, Japan

\section{Competing interests}

The authors declare that they have no competing interests.

Received: 19 February 2011 Accepted: 25 May 2011

Published: 25 May 2011

\section{References}

Becker DM, Guarente L (1991) High-efficiency transformation of yeast by electroporation. Methods Enzymol 194:182-187

Gellissen G, Hollenberg CP (2004) Encyclopedia of Food Microbiology. Hansenula 976-982

lefuji H, limura Y, Obata T (1994) Isolation and characterization of a yeast Cryptococcus sp. S-2 that produces raw starch-digesting a-amylase, xylanase, and polygalacturonase. Biosci Biotechnol Biochem 58:2261-2262. doi:10.1271/ bbb.58.2261.

lefuji H, Chino M, Kato M, limura Y (1996) Raw-starch-digesting and thermostable a-amylase from the yeast Cryptococcus sp. S-2: purification, characterization, cloning and sequencing. Biochem J 318:989-996

lefuji H, Chino M, Kato M, limura Y (1996) Acid xylanase from yeast Cryptococcus sp. S-2: purification, characterization, cloning, and sequencing. Biosci Biotechnol Biochem 60:1331-1338. doi:10.1271/bbb.60.1331.

Kamini NR, Fujii T, Kurosu T, lefuji H (2000) Production, purification and characterization of an extracellular lipase from the yeast, Cryptococcus sp. S-2. Process Biochem 36:317-324. doi:10.1016/50032-9592(00)00228-4.

Kato M, lefuji H, Miyake K, limura Y (1997) Transformation system for a wastewater treatment yeast, Hansenula fabianii J640: isolation of the orotidine-5'-phosphate decarboxylase gene (URA3) and uracil auxotrophic mutants. Appl Microbiol Biotechnol 48:621-625. doi:10.1007/s002530051105.

Kato $\mathrm{M}$, Kitajima T, lefuji $\mathrm{H}$ Isolation and characterization of glucoamylase from a wastewater treatment yeast Hansenula fabianii J640, and construction of expression vector. Appl Microbiol Biotechnol (in press)

Moriya K, lefuji H, Shimoi H, Sato S, Tadenuma M (1990) Treatment of distillery wastewater discharged from beet molasses-spirits production using yeast. J Ferment Bioeng 69:138-140. doi:10.1016/0922-338X(90)90204-A.

Ogata T, limura Y, Obata T, Tamura G (1992) Isolation and nucleotide sequence of Hansenula anomala URA3 gene encoding orotidine-5'- phosphate decarboxylase. J Ferment Bioeng 74:352-357. doi:10.1016/0922-338X(92)90030-X.

Ogata T, Okumura Y, limura Y, Obata T (1995) Development of an integrative DNA transformation system for the yeast Hansenula anomala. J Ferment Bioeng 79:1-5. doi:10.1016/0922-338X(95)92734-T.

Saito K, Nakao T, Shima Y, Shimoi H, Sato S, Tadenuma M (1987) Utilization of waste water discharged from pot-still during spirits-making. J Brew Soc Jpn 82:444-446

Sato S, Maetani T, Yamamoto N, Hasuo T, Tadeuma M, Yoshizawa K (1986) Selection of flocculent yeast and its application to waste water treatment. J Brew Soc Jpn 81:621-625
Sato S, Otani M, Shimoi H, Saito K, Tadenuma M (1987) Selection of flocculent mutants of waste water treatment utilization of wild yeasts. J Brew Soc Jpn 82:515-519

Schena M, Picard D, Yamamoto KR (1991) Vectors for constitutive and inducible gene expression in yeast. Methods Enzymol 194:389-398

Steinborn G, Böer E, Scholz A, Tag K, Kunze G, Gellissen G (2006) Application of a wide-range yeast vector $\left(\mathrm{CoMed}^{\mathrm{TM}}\right)$ system to recombinant protein production in dimorphic Arxula adeninivorans, methylotrophic Hansenula polymorpha and other yeasts. Microb Cell Fact 5:33. doi:10.1186/1475-2859-533.

Suzuki O, Sato S, lefuji H, Shimoi H, Tadenuma M, Yoshizawa K (1991) Utilization of thermotolerant and flocculent yeast for wastewater treatment. Hokkokogaku Kaishi 69:83-87

Suzuki O, Kobari O, lefuji H, Akita O (1996) Breeding of yeast for waste water treatment by protoplast fusion. J Brew Soc Jpn 91:521-526

Yamada-Onodera K, Ono K, Tani Y (1999) Purification and characterization of an enzyme that has dihydroxyacetone-reducing activity from methanol-grown Hansenula ofunaensis. J Biosci Bioeng 88:148-152. doi:10.1016/S1389-1723(99) 80193-5.

Yamada-Onodera K, Nakajima A, Tani Y (2006) Purification, characterization, and gene cloning of glycerol dehydrogenase from Hansenula ofunaensis, and its expression for production of optically active diol. J Biosci Bioeng 102:545-551. doi:10.1263/jbb.102.545.

Yoshizawa K (1978) Treatment of waste-water discharged from a Sake' brewery using yeast. J Ferment Technol 56:389-395

Yoshizawa K (1981) Development of the new treating methods of waste water from food industry using yeast. Nippon Nogeikagaku kaishi 55:705-711

doi:10.1186/2191-0855-1-7

Cite this article as: Kato and lefuji: Breeding of a new wastewater treatment yeast by genetic engineering. AMB Express 2011 1:7.

\section{Submit your manuscript to a SpringerOpen ${ }^{\mathcal{O}}$ journal and benefit from:}

- Convenient online submission

- Rigorous peer review

- Immediate publication on acceptance

- Open access: articles freely available online

- High visibility within the field

- Retaining the copyright to your article

Submit your next manuscript at $>$ springeropen.com 